\title{
Antifungal activity and GC-MS detection of leaves and roots parts of Chenopodium album extract against some phytopathogenic fungi
}

Jawadayn Talib Alkooranee, Hasan Hadi Al-khshemawee, Mutaz Abdul Kadhim Al-badri, Maha Shaker Al-srai, Hadeel Hamazah Daweri

10.18805/IJARe.A-433

\begin{abstract}
Antifungal potential of leaves and roots parts of Chenopodium album was evaluated against five phytopathogenic fungi including Alternaria alternata, Fusarium solani, Rhizoctonia solani, Pythium aphanidermatum and Sclerotinia sclerotium using four concentrations viz. $0,5,10$ and $15 \%$ of leaves and roots water extract led to significantly reduced of fungi mycelial growth. GC-MS analysis of leaves and roots water extract showed the presence of 7 compounds. $2(3 \mathrm{H})$-furanone, dihydro-4,4-dimethyl; 9-octadecenoic acid $(\mathrm{Z})$, methyl ester; 9,12-octadecenoic acid (Z), methyl ester; 6-methylene bicyclo (3.2.0) hept-3-en-2-one., 1,2-benzene dicarboxylic acid, mono (2-ethylhexyl) ester and hexadecanoic acid, methyl ester. Five phytopathogenic fungi could be managed and controlled by the water leaves and roots extract of $C$. album. The antifungal activity of this extract was possible could be used to control a wide range of fungi.

Key words: Alternaria alternata, Chenopodium album, Fusarium solani, GC-MS, Pythium aphanidermatum, Rhizoctonia solani, Sclerotinia sclerotiurm.
\end{abstract}

\section{INTRODUCTION}

Chenopodium album Linn. is an annual shrub, polymorphous, erect herb, mealy white, up to $3.5 \mathrm{~m}$ in height and widely. It has been grown in Asia, Africa, North America and Europe (Agrawal et al., 2014). The tender shoots are cooked as a vegetable and eaten raw with curd or in a salad; as well as it is also used as fodder (Pande and Pathak, 2010). C. album is very nutritious and rich in vitamin C, vitamin $A$, calcium, protein, iron, potassium and phosphorus, content. It is used as the laxative, anthelmintic against hookworms and round, as spleen enlargement, blood purifier in hepatic disorders, burns and intestinal ulcers. Also, it has been used as folk medicine and bioactivities such as antifungal, antinociceptive, antipruritic and hypotensive properties of crude (Agrawal et al., 2014). Recently, C. album has spread heavily during winter and summer in gardens, the field of barley and wheat of Wasit province in Iraq. The major factor for the spread and persistence of $C$. album is their ability to resist diseases and pests compared with the field crops in their environment. Thus, it can be a potential source of anti-phytopathogens compounds and their identification is needful to develop fungicides. It could be cheap and produced from plants available in the environment.

Chemical fungicides are mostly using to control plant disease of fungi because of their high effectiveness. However, many of their disadvantages cause environmental pollution, diseases for humans and animals. The killing of beneficial insects, also, most pathogenic fungal strains began to resist many types of these fungicides (Kamurthy et al., 2016).
Department of Plant Protection, College of Agriculture, Wasit University, Wasit, Iraq.

Corresponding Author: Jawadayn Talib Alkooranee, Department of Plant Protection, College of Agriculture, Wasit University, Wasit, Iraq. Email: jalkooranee@uowasit.edu.iq

How to cite this article: Alkooranee, J.T., Al-khshemawee, H.H., Al-badri, M.A.K., Al-srai, M.S. and Daweri, H.H. (2020). Antifungal activity and GC-MS detection of leaves and roots parts of Chenopodium album extract against some phytopathogenic fungi. Indian Journal of Agricultural Research. 54(1): 117-121.

Submitted: 23-03-2019 Accepted: 13-07-2019 Published:09-11-2019

Plant extracts played an important role in inhibiting the growth of various pathogenic pathogens in the soil and improving the quality of plant seeds. Thembo et al. (2010) pointed that the possibility of using chemical extracts from some of the weeds as fungicides that environmentally friendly and they have been tested four weed plants such as Lippia javanica, Tagetes minuta, Vigna unguiculata and Amaranthus spinosus against four isolates of phytopathogen fungi, Aspergillus parasiticus, A. flavus, Fusarium proliferatum and $F$. verticillioides.

The water and alcoholic extracts of Oxalis corniculata and Mimosa pudica weeds were tested as antifungal against fungus Candida Albicans; they showed high efficiency in inhibition to the pathogen (Kamurthy et al., 2016). Based on that, we selected $C$. album weed to the absence of fungal infections on their stems and leaves. In Iraq, the antifungal activity of leaves and roots of $C$. album extracts of this 
Antifungal activity and GC-MS detection of leaves and roots parts of Chenopodium album extract against some....

species has not been previously reported, the aim of our objective was to the identification of compounds extracted using GS-MS and test the efficacy of this compounds to inhibit mycelial growth of some phytopathogens invitro. Therefore, the main aim of this study to understand the secret of $C$. album resistance to plant pathogens and the diagnosis of compounds extracted from its roots and leaves. Also, to identify the possibility of using them to control various plant diseases as an alternative to synthetic fungicides.

\section{MATERIALS AND METHODS}

\section{Plant materials}

Leaves and roots of $C$. album were collected from Wasit University during March 2018. It is identified by at Field Crop Department, College of Agriculture, Wasit University. Herbarium of $C$. album was prepared and preserved in the Crop field laboratory, Wasit University. The roots have been separated from the stem by a sharp blade and washed by rinsing in tap water. They allowed to dry and then dried by electric oven at $75^{\circ} \mathrm{C}$. The plant materials were ground to a fine powder using a mechanical grinder.

\section{Fungal pathogens}

Five isolates of phytopathogens fungi $A$. alternata, F. solani, $R$. solani, P. aphanidermatum and S. sclerotium were obtained from the Field Crops Department, Agriculture College, Wasit University, Wasit, Iraq. These fungi have been grown in Potato dextrose agar (PDA) media with autoclaved at $120^{\circ} \mathrm{C}$ for $20 \mathrm{~min}$.

\section{Preparations of water extracts}

Two hundred gram of $C$. album were soaked in $1 \mathrm{~L}$ of distilled water separately and incubated overnight. Then, filtered through a Whatmann No. 41 filter paper. The filtered extract has been evaporated by a rotary evaporator and oven dried at $45^{\circ} \mathrm{C}$. Different concentrations $0,5,10$ and $15 \%$ of dried powder extraction were prepared from leaves and roots dry powder to $100 \mathrm{ml}$ sterilized distilled water separately. After that, they are ready to use them in inhibition growth of pathogens fungi.

\section{Antifungal activity}

To determine the effects of the leaves and roots of $C$. album water extract on the mycelia length growth of pathogens in dual-culture techniques. Four concentration 0, 5, 10 and $15 \%$ concentrations have been added as $3 \mathrm{ml}$ for each concentration into $60 \mathrm{ml}$ sterilized P.D.A media $\left(40^{\circ} \mathrm{C} \pm 2^{\circ} \mathrm{C}\right)$ separately. The media was mixed properly and poured into Petri dishes and then inoculated with 5-mm mycelia plugs of the pathogens placed in the centers of the plates separately. Control treatments consisted of PDA and disks of pathogens, without filtered extract. There were three repeated plates for each concentration per pathogen. The inoculated plates have been incubated at $27^{\circ} \mathrm{C} \pm 1^{\circ} \mathrm{C}$ until the fungus grows completely in the control dish. Percent mycelia growth inhibition was calculated according to the following formula:

\author{
Percent inhibition $=\mathrm{C}-\mathrm{T} / \mathrm{C}$ * 100
}

$\mathrm{C}=$ Control of radial growth of the pathogen,

$\mathrm{T}=$ Treatment of radial growth of the pathogen with leaves or roots of $C$. album water extract.

\section{GC-MS analysis}

GC-MS 7820A gas chromatography equipped with detector 5977E mass spectrometer (Agilent Technologies, USA). Helium was used as a carrier gas with $99.999 \%$ supplied by (BOC, gas, Sydney, AU). Inlet temperature of the instrument was $250^{\circ} \mathrm{C}$. Oven was preset at $50^{\circ} \mathrm{C}$ for $5 \mathrm{~min}$, raised up to $250^{\circ} \mathrm{C}$. The total run time for equipment was $45 \mathrm{~min}$. the flow rate was $0.7 \mathrm{ml} / \mathrm{min}$, the split less was $20 \mathrm{ml} / \mathrm{min}$ at 1.5 $\mathrm{min}$. The total run time for equipment was $45 \mathrm{~min}$. The compounds were identified by comparison of the mass spectrum with the US National Institute of Standards and Technology (NIST, 2014) database.

The samples have been analyzed in biosecurity lab., Murdoch University, Australia. Limit of detection (LOD) has been identified in this study as well. Alkane standard C7C30 (Supelco, Bellefonte, USA) has been used to identify limit of detection. One microliter of standard was used in injection into GC-MS with $250^{\circ} \mathrm{C}$ injection port.

\section{Statistical analysis}

In vitro experiments, three replicates were performed for each treatment according to the randomized design of the experimental experiments. The results data were analyzed for the variance using by Principal component analysis (PCA) and One-way Analysis of Variance (ANOVA) methods using online MetaboAnalyst 3.0 a comprehensive tool for metabolomics analysis and interpretation.

\section{RESULTS AND DISCUSSION \\ Antifungal activity}

The results of Invitro screening showed that the ability of $C$. album water extraction to inhibition of radial growth of some fungi pathogens. The percent mycelial inhibition of Alternaria alternata, Fusarium solani, Rhizoctonia solani, Pythium aphanidermatum and Sclerotinia sclerotium reached at 5 $\%$ concentration of leaves water extract at 27.90, 8.55, 20.12, 10.73 and $3.52 \%$ respectively, while reached $48.18,37.62$, $62.40,74.26$ and $40.52 \%$ respectively at $10 \%$ concentration and reached $100,83.60,100,9.33$ and $91.42 \%$ respectively at $15 \%$ concentration. For roots water extract at $5 \%$ concentration, it reached $32.18,17.76,21.60,16.30$ and $19.00 \%$ respectively, while reached $63.80 \%, 71.95,78.10$, 80.46 and $85.15 .52 \%$ respectively at $10 \%$ concentration and reached $100 \%$ for all fungi at $15 \%$ concentration. Where reached at $15 \%$ concentration of leaves water extract at $100 \%, 83.60 \%, 100 \%, 9.33 \%$ and $91.42 \%$ respectively, while reached $48.18,37.62,62.40,74.26$ and $40.52 \%$ respectively at $10 \%$ concentration. For roots water extract at $15 \%$ concentration, it reached $100 \%$ for all fungi growth. While reached $63.80 \%, 71.95,78.10,80.46$ and $85.15 .52 \%$ respectively at $10 \%$ concentration. However, mycelia 
Antifungal activity and GC-MS detection of leaves and roots parts of Chenopodium album extract against some....

inhibition of all fungi reached $0 \%$ at 5 and $0 \%$ concentration of both leaves and roots water extract (Table 1).

There are evidence from earlier studies that various weed species possess antifungal properties, lqbal et al. (2001) found that the growth of mycelial growth of Phomopsis theae, Aspergillus niger and Rhizoctonia solani was reduce after treated with water extracts of Phyllanthus debilis, Desmodium trifolium, Ageratum conyzoides, Vernonia cinerea and Oxalis corniculata weed species. Some extracts of $C$. album such as roots, leaves, stem and inflorescence were examined against $F$. oxysporumf. sp. cepae at different concentrations $(0.5,1.0,3.0 \%)$ extract suppressed pathogen growth by $2.5-100 \%$ (Rauf and Javaid, 2013).C. album has been found to have cinnamic acid amide, saponin, phenolic amide, apocortinoid, alkaloid chinoalbicin, lignans, phenols and xyloside as active phytoconstituents (Agrawal et al., 2014). Kamurthy et al. (2016) reported that some compounds extracted from weeds including, phenolic compounds, organic acids, malic acid, steroids, tannins, glycosides, triterpenoids, tartaric acid, alkaloids, flavonoids and citric acid may have the important role on inhibition of C. albicans growth.

\section{GC-MS detection}

GC-MS has been detected seven main compounds belonging to the aromatic dicarboxylic ester, fatty acid methyl esters and ketone groups which water leaves and roots extract from $C$. album (Table 2). The peak areas for these compounds were 6-methylenebicyclohept- 3-en-2-one (159.984); 1,2-Benzenedicarboxylic acid, mono(2ethylhexyl) ester (377.746); 23h-furanone, dihydro-4,4- dimethyl (288.391); hexadecanoic acid, methyl ester (211.644); 9-octadecenoic acid (Z)-, methyl ester (153.649); 9,12-octadecadienoic acid (Z,Z)-, methyl ester (58.281) and farnesene (86.406) (Table 2). The names of compounds are shown alongside comparison with molecular formulas, molecular weights and time retention of the NIST database and peak areas in Table 2. Some of these compounds belong to the methyl ester, methyl ethylethyl, methyl ethyl group, linoleic, Esther and fatty acids (Agoramoorthy et al. 2007., Chandrasekharan et al. 2008., Lima et al. 2011., Hussein et al. 2016).

Agoramoorthy et al. (2007) have been described that the methyl esters and fatty acid were known to possess antifungal properties. Khurshid et al. (2018) have been evaluated the antimicrobial activity of methanolic leaf, stem and inflorescence extract of Cenchrus pennisetiformis against Fusarium oxysporum f. sp. lycopersici causing wilt disease in tomato, they found that the grass significantly reduced fungal biomass and GC-MS analysis showed the presence of 10 compounds 1-eicosene, 1-propanol2-2hydroxypropxy, benzofuran 2,3-dihydro, hexadecanoic acid, ethyl-ester, Phenol, 2,4-bis, 1,1-dimethlethyl, Heptanal, 2[phenylmethylene]-, E-15-heptadecenal, Ethanone, 1-[2,4,5tri ethoxypenyl]- and Benzene, 1-[1,1-dimethylethyl]-3,5dimethyl-2,4,6-trinitro. Fatty acid of seeds of Annona cornifolia, have been examined by Lima et al. (2011), palmitic acid methyl ester (16.9\%), linoleic acid methyl ester (19.1\%) and mainly oleic acid methyl ester (51.5\%). Heat map and ANOVA analyses in these experiments have been described the differences of the compounds with their peak areas. The PCA visualizes both the covariance and correlation between

Table 1: In vitro screening the leaves and roots of $C$. album water extraction to inhibition of radial growth of some fungi pathogens.

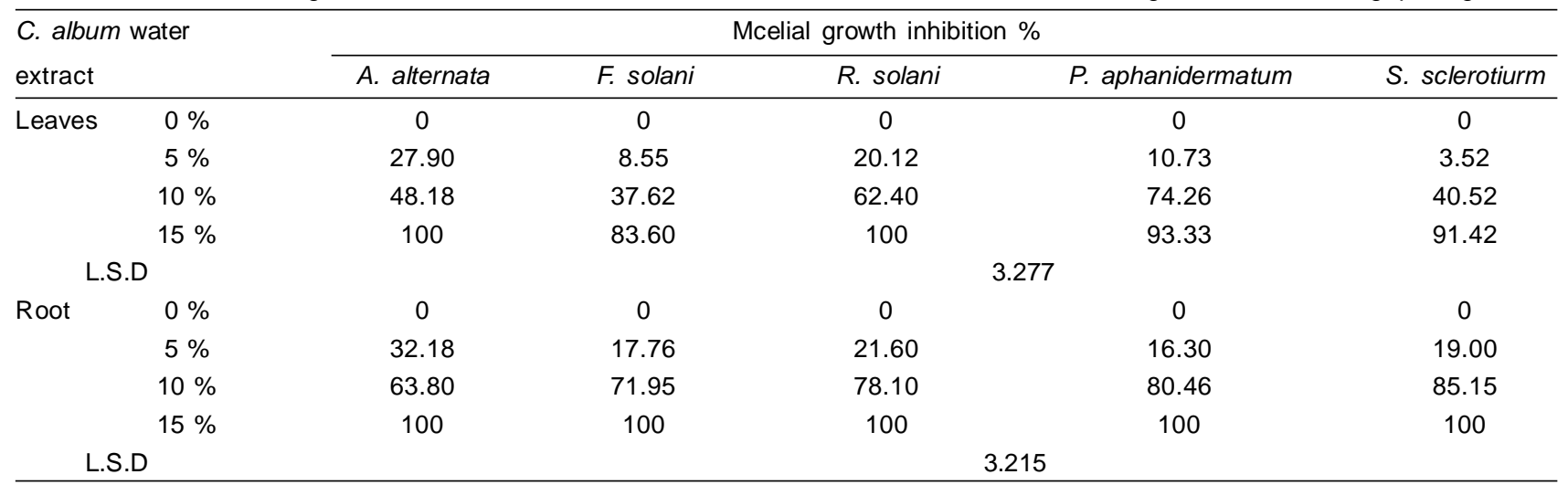

Table 2: Compounds were identified (one unit corresponds to a $10^{4}$ area) from leaves and roots extract of $C$. album using GC-MS analysis.

\begin{tabular}{lcccc}
\hline Compounds & RT & Peak area & p-value & FDR \\
\hline 23H-Furanone, dihydro-4,4-dimethyl & 9.008 & 288.391 & 0.002 & 0.093 \\
Hexadecanoic acid, methyl ester & 10.743 & 211.644 & 0.033 & 0.117 \\
9,12-Octadecadienoic acid Z,Z-, methyl ester & 17.886 & 58.381 & 0.306 & 0.672 \\
6-Methylenebicyclo3.2.0hept-3-en-2-one & 9.523 & 159.984 & 0.439 & 0.672 \\
Farnesene & 18.322 & 86.406 & 0.539 & 0.571 \\
1,2-Benzenedicarboxylic acid, mono2-ethylhexyl ester & 24.654 & 377.746 & 0.646 & 0.621 \\
9-Octadecenoic acid Z-, methyl ester & 20.110 & 153.649 & 0.672 & 0.653 \\
\hline
\end{tabular}




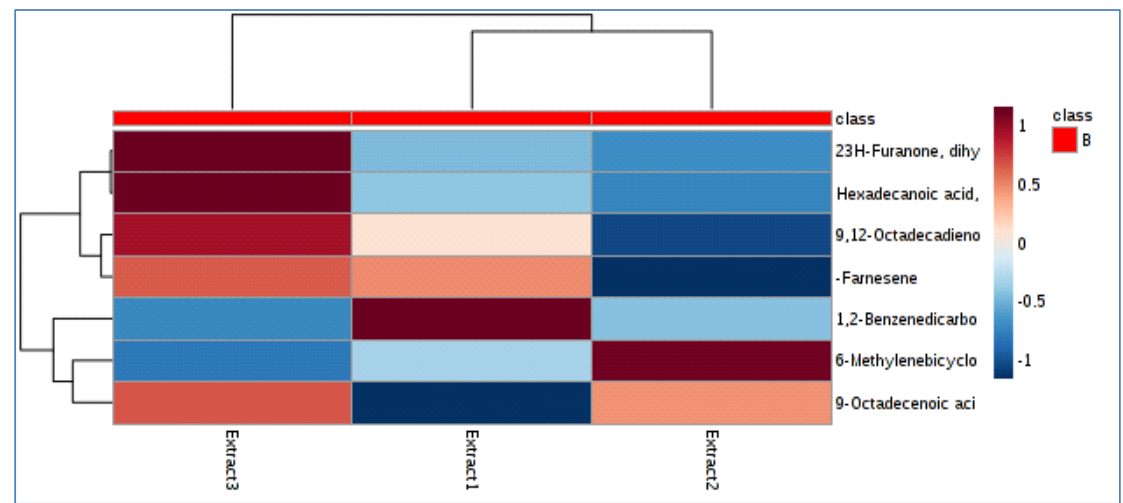

Fig 1: Heat map showing the changes of abundance values normalized to the compounds that are significantly influenced.

the metabolites and the modeled class designation. Thereby the PCA-plot helps to identify statistically significant and potentially biochemically significant metabolites based both on contributions to the model and their reliability. An extension of the PCA, the heat map, was applied to compare the outcome of multiple classification models compared the peak area. The used example is a GC coupled MS-based metabolomics study in extracted samples were extracted from the weed seeds (Fig1). In the current study, the method explain inhibited the growth of five phytopathogenic fungi Alternaria alternata, Fusarium solani, Rhizoctonia solani, Pythium aphanidermatum and Sclerotinia sclerotiurm. Based on Agoramoorthy et al. (2007) showed the ability of fatty acid methyl ester extract of $E$. agallocha to suppressed growth of four species of Candida including C. parapsilosis, C. tropicalis, C. albicans and $C$. krusei because it is rich in palmitic acid methyl ester (56.02\%). The 6-methylenebicyclo (3.2.0) hept-3-en-2-one has been used to show normalization of the compounds that are significantly influenced 1,2-benzene dicarboxylic 5acid and for mono (2ethylhexyl) ester has been used successfully from marine metabolites of a cyanobacterium Oscillatoria terebriformis, Alternaria sp. and Streptomyces sp.

This compound has been used for a large number of biological studies, including cytotoxicity, anti-inflammatory, antioxidant, antimicrobial and antiviral activity (Mukund et al, 2014., Krishnan et al, 2014; Govindappa et al, 2014). It was a major compound, which has been found in the current study (377.746). Therefore, there was a possibility that it may have had a role in the antifungal activity of water leave and roots extract of $C$. album in this study.

\section{CONCLUSION}

As a result of the spread of this weed in a wide area of Iraq, it can be used as an environment-friendly fungicide. It can also be managed many important diseases that affect the fields of wheat and barley, which are grown primarily in Iraq instead of using the pesticides. This study concluded that the five phytopathogenic fungi $A$. alternata, $F$. solani, $R$. solani, $P$. aphanidermatum and $S$. sclerotium could be managed and control by the water leaves and roots extract of $C$. album. Antifungal activity of these extracts can be used to control a wide range of phytopathgens.

\section{ACKNOWLEDGMENT}

The authors would like to acknowledge Wasit University and Murdoch University to their support. We would like to thankful Dr. Nabel from Wasit University, Field Crop Department for identifing the weed and for the help in statistical analysis. Many thanks for everyone who helped in this study.

\section{REFERENCES}

Agoramoorthy, G., Chandrasekaranll, M., Venkatesalull, V., HsullI, M.J. (2007). Antibacterial and antifungal activities of fatty acid methyl esters of the blind-your-eye mangrove from India. Braz J Microbiol. 38: 739-742.

Agrawal, M.Y., Agrawal, Y.P., Shamkuwar, P.B. (2014). Phytochemical and biological activities of Chenopodium album. International Journal of PharmTech Research. 6(1): 383-391.

Chandrasekharan, M., Kannathasan, K., Venkatesalu, V. (2008). Antimicrobial activity of fatty acid methyl esters of some members of chenopodiaceae. Z Naturforsch C. 63: 331-6.

Govindappa, M., Somu, P., Vinay, V., Ryavalad, C. (2014). Chemical composition of methanol extract of endophytic fungi, Alternariasp. of Tebebuia argentea and their antimicrobial and antioxidant activity. Int $\mathrm{J}$ Biol Pharm Res. 5: 861-9.

Hussein, H.J., Hadi, M.Y., Hameed, I.H. (2016). Study of chemical composition of Foeniculum vulgare using Fourier transform infrared spectrophotometer and gas chromatographymass spectrometry. J Pharm Phytother. 8: 60-89.

Iqbal, M.C.M., Meiyalaghan, S., Wijesekara, K.B., Abeyratne, K.P. (2001). Antifungal activity from water extracts of some common weeds. Pakistan Journal of Biological Sciences. 4(7): 843-845.

Kamurthy, H., Tejmal, M., Majumder, P., Ambujakshi, H.R. (2016). Antifungal activity of weed extracts on Candida albicans an in-vitro study. International Journal of Phytomedicine. 8: 453-456.

Khurshid, S., Javaid, A., Shoaib, A., Javed, S., Qaisar, U. (2018). Antifungal activity of aerial parts of Cenchrus pennisetiformis against Fusarium oxysporum f. sp. lycopersici. Planta Daninha. 36: e017166627.

Krishnan, K., Mani, A., Jasmine, S. (2014). Cytotoxic activity of bioactive compound 1, 2- benzene dicarboxylic acid, 
Antifungal activity and GC-MS detection of leaves and roots parts of Chenopodium album extract against some....

mono 2- ethylhexyl ester extracted from a marine derived Streptomyces sp. VITSJK8. Int J Mol Cell Med. 3: 246.

Lima, L.A., Johann, S., Cisalpino, P.S., Pimenta, L.P., Boaventura, M.A. (2011). In vitro antifungal activity of fatty acid methyl esters of the seeds of Annona cornifolia A.St.-Hil. (Annonaceae) against pathogenic fungus Paracoccidioides brasiliensis. Rev Soc Bras Med Trop. 44: 777-80.

Mukund, S., Jegan, G., Palanisamy., Muthukumaran, M., Sivasubra -manian, V. (2014). GC-MS and FT-IR analysis of some bioactive constituents from Oscillatoria terebriformis. Indian J Pharm Sci Res. 4: 102-7.
Pande, M., Pathak, A. (2010). Preliminary Pharmacognostic evaluations and phytochemical studies on leaf of Chenopodium Album (Bathua Sag). Asian J. Exp. Biol. Sci. 1(1): 91-95.

Rauf, S., Javaid, A. (2013). Antifungal activity of different extracts of Chenopodium album against Fusarium oxysporum $\mathrm{f}$. sp. cepae, the cause of onion basal rot. International Journal of Agriculture and Biology. 15: 367371.

Thembo, K.M., Vismer, H.F., Nyazema, N.Z., Gelderblom, W.C., Katerere, D.R. (2010). Antifungal activity of four weedy plant extracts against selected mycotoxigenic fungi. J Appl Microbiol. 109(4): 1479-1486. 